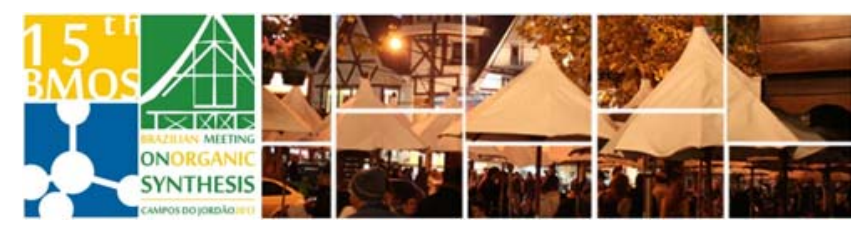

\title{
Chemoselective Transformations for Bioimaging and Targeted Therapeutics
}

\author{
Gonçalo J. L. Bernardes \\ ${ }^{1}$ Department of Chemistry, University of Cambridge, Lensfield Road, Cambridge CB2 1EW, UK \\ ${ }^{2}$ Instituto de Medicina Molecular, Faculdade de Medicina da Universidade de Lisboa, Av. Prof. Egas Moniz, \\ 1649-028 Lisboa, Portugal; website: www.gbernardes-lab.com \\ *e-mail corresponding author: gb453@cam.ac.uk
}

Keywords: Aqueous reactions; site-selective protein modification; targeted therapeutics

\section{ABSTRACT}

Covalent protein modification is a key instrument in Chemical Biology: attachment of biophysical probes enable protein tracking and imaging; attachment of lipids to small therapeutic peptides extends their half-life in circulation; and protein conjugates are important biologic targets for the treatment of human diseases. In addition, proteins are modified after translation, increasingly significantly their structural complexity and functional capability. The use of efficient, complete, chemo- \& regioselective methods in benign aqueous systems offers ways to redesign the structure and function of proteins of biological and therapeutic interest.

This abstract features examples of (a) precise and controlled methods for site-specific protein labeling in vitro $^{[1,2]}$; (b) development of chemically-defined, traceless therapeutic proteins for cancer therapy ${ }^{[3-5]}$ and (c) controlled delivery of therapeutic $\mathrm{CO}$ using chemicallydefined carbonyl metalloproteins ${ }^{[6-8]}$.

\section{REFERENCES}

(1) Bernardes, G. J. L.; Chalker, J. M.; Errey, J. C.; Davis, B. G. J. Am. Chem. Soc. 2008, 130, 5052-5053.

(2) Chalker, J. M.; Bernardes, G. J. L.; Davis, B. G. Acc. Chem. Res. 2011 44, 730-741.

(3) Bernardes, G. J. L.; Casi, G.; Trüssel, S.; Hartmann, I.; Schwager, K.; Scheuermann, J.; Neri, D. Angew. Chem. Int. Ed. 2012, 51, 941-944.

(4) Steiner, M.; Hartmann, I.: Perrino, E.; Casi, G.: Brighton, S.; Jelesarov,

I.; Bernardes, G. J. L.; Neri, D. Chem. Sci. 2013, 4, 297-302.

(5) Bernardes, G. J. L.; Steiner, M.; Hartmann, I.; Neri, D.; Casi, G. Nat. Protocols 2013, 8, 2079-2089.

(6) Santos-Silva, T.; Mukhopadhyay, A.; Seixas, J. D.; Bernardes, G. J. L. Romão, C. C.; Romão, M. J. J. Am. Chem. Soc. 2011, 133, 1192-1195.

(7) Romão, C. C.; Blättler, W. A.; Seixas, J. D.; Bernardes, G. J. L. Chem. Soc. Rev. 2012, 41, 3571-3583.

(8) Pena, A. C.; Penacho, N.; Mancio-Silva, L.; Neres, R.; Seixas, J. D.; Fernandes, A. C.: Romão, C. C.; Mota, M. M.; Bernardes, G. J. L.; Pamplona, A. Antimicrob. Agents Chemother. 2012, 56, 1281-1290. 